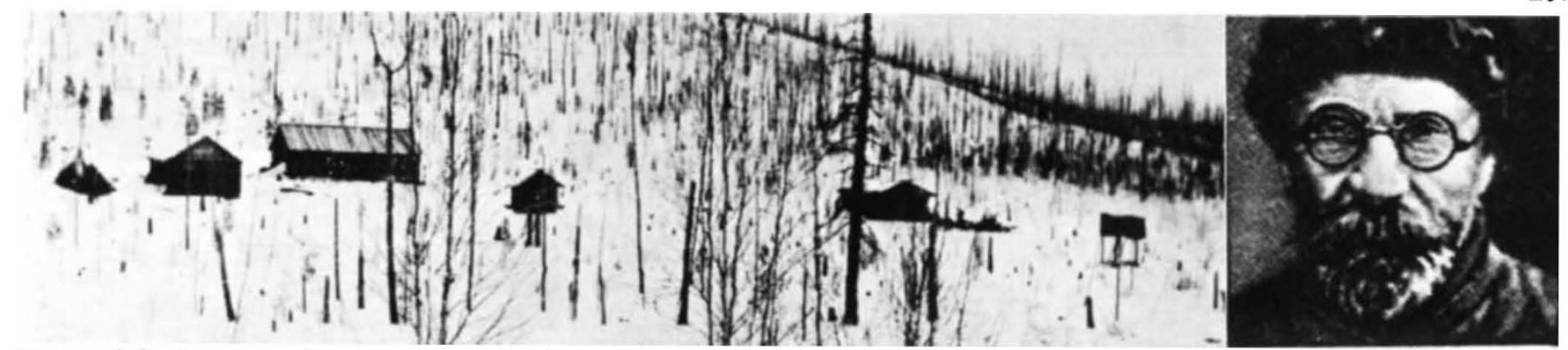

Forest of dead trees at the centre of the explosion area. The huts in this 1931 photograph are those of explorer Kulik (right).

\title{
The 70-year-old mystery of Siberia's big bang
}

QEVENTY years ago this month, a

Miss Katharine Stephen of Godmanchester, Huntingdon, wrote to The Times, commenting, in somewhat poetic terms, on the "strange light in the sky" which she and her sister had observed between midnight and 12.15 a.m. on July 1. "It would be interesting", she wrote, "if anyone could explain the cause of so unusual a sight".

Seventy years later, her question, and that of the many others who wrote to the press, remains unanswered. The T'imes did its best with suggestions of the aurora borealis, possibly associated with a large solar prominence currently under observation-or, alternately, debris from a Krakatoa-like but unrecorded volcanic eruption in some "little-known region of the world".

The source of the light did, indeed, lie in such a region-Siberia. But in those distant Tsarist times, the news which was relayed from St Petersburg to London was somewhat restricted. The few reports which appeared in local Siberian papers-in one case nearly two months after the event-never reached the notice of the St Petersburg correspondents.

A few rumours do seem to have trickled through and affected the fiction of the time-one pre-1914 short story (or rather "tall story") told of an explorer in Siberia who located a "lake" of solid diamond-produced by a meteorite which had hit a coal-seam. (The "lake" was, naturally, swallowed without trace by an earthquake before it could be exploited.)

Not until 1927, however, was any attempt made to locate the site of the Filimonovo meteorite when Leonid A. Kulik led an expedition to Siberia. (According to one unsubstantiated report, during the passage of the fireball a train had been halted at Filimonovo junction).

The penetration of Siberia and its incorporation into the new Soviet economy was of great symbolic importance to the Russian leaders of the time-many of whom had spent long years as exiles there. The unexploited wealth of Siberia was proverbial-and the postulated giant meteorite might well have represented at least, psycho- logically, an important economic asset.

What Kulik found, however, several days reindeer-journey from the Stony Tunguska river, was not a meteorite but a scene of weird devastationradical fans of flattened trees with a small plantation standing without branches at the apparent epicentre. The "meteorite", if it existed, was never found.

The wrecked terrain presented a mystery, but was accepted without undue comment until 1945, when similar blast phenomena were observed at Hiroshima and Nagasaki. Suggestions soon began to appear that the disasters were similar in origin. It was recalled that the local population maintained that after the explosion, the reindeer had suffered from mysterious scabs. Tree-ring evidence suggested an enormous acceleration in growth rates since 1908-also characteristic of the nuclear-bombed cities. The "pillar of fire" which some natives recollected (20 years after the event) could well be called a mushroom cloud! Tunguska was to become, in the popular imagination, a nuclear explosion.

No one ever seems to have considered whether any of these phenomena are or could be characteristic of powerful explosions in general, rather than specific to nuclear devices. (Were the scabs on the reindeer, for example, simply burns from hot ash? What of the burgeoning of vegetation in conventionally-bombarded cities? Could an ultra-powerful but non-nuclear explosion produce a similar blast pattern?) The 'nuclear' hypothesis appealed to certain imaginations both in and outside the Soviet Union; particularly when this hypothesis was 'explained' by a postulated disaster to an extraterrestrial spacecraft! Moving from science-fiction towards science, the riddle of Tunguska attracted a wide range of explanations-a giant ball of ice and snow, which melted, ball lightning of unprecedented size, antimatter, a black hole. . . By 1976, Igor Zotkin of the Committee of Meteorites of the Soviet Academy of Sciences could write: "I doubt if there is any recent discovery that has not been called on to explain the Tunguska

\section{enigma".}

The most recent expeditions have paid considerable attention to vitreous particles found in the peat bogs of the area and to the slight but definite increase in the radioactivity of the surviving trees in the area. As a result of their findings conventional Soviet opinion, as exemplified by Academician Georgii Petrov, Professor Nikolai Vasil'ev, and Vitalii Bronsten, now believes that the Tunguska explosion was caused by a small comet disintegrating in the atmosphere. (Certainly, the blast patterns suggest an aerial explosion). However, Professor Feliks Zigel of the Moscow Aviation Institute, drawing on eyewitness accounts (taken down some 15-20 years after the event), maintains that the body changed direction twice before impact and was hence a UFO.

And Alekesi Zolotov of Kalinin, described by Moscow radio in its anniversary programme as "another noted investigator" sticks firmly to his own explanation-a nuclear explosion of possibly, extraterrestrial, origin.

Zolotov is, incidentally, a Tunguska enigma in himself. His name turns up unfailingly in any discussion of the problem, and his theories, however bizarre to the scientific establishments, do at least get published. This in the Soviet academic system with its emphasis on procedure and its demand that each new piece of research be counter-signed by the head of department or institute is surprising in itself. Yet his own academic background seems obscure, and according to one physicist who worked for many years on the Tunguska site, Zolotor was originally simply an oil technologist, co-opted on to an expedition for his knowledge of the local terrain!

To celebrate the 70th anniversary of the "event" yet another expedition is to be launched this year. "Let us wait" said a Tass radio-commentary "for new facts to be elicited in the scientists' laboratories!" A laudable sentiment. But, if the expedition runs true to form, it may well produce yet a further crop of legends.

Vera Rich 